\title{
Emmetropisation following preterm birth
}

\author{
K J Saunders, D L McCulloch, A J Shepherd, A G Wilkinson
}

Br J Ophthalmol 2002;86:1035-1040

Background/aims: Even in the absence of retinopathy of prematurity (ROP), premature birth signals increased risk for abnormal refractive development. The present study examined the relation between clinical risk factors and refractive development among preterm infants without ROP.

Methods: Cycloplegic refraction was measured at birth, term, 6, 12, and 48 months corrected age in a cohort of 59 preterm infants. Detailed perinatal history and cranial ultrasound data were collected. 40 full term (plus or minus 2 weeks) subjects were tested at birth, 6, and 12 months old.

See end of article for authors' affiliations .....................

Correspondence to: Dr K J Saunders, School of Biomedical Science, University of Ulster, Coleraine, Northern Ireland, BT52 1SA; ki.saunders@ulst.ac.uk

Accepted for publication 10 April 2002
Results: Myopia and anisometropia were associated with prematurity $(p<0.05)$. More variation in astigmatic axis was found among preterm infants $(p<0.05)$ and a trend for more astigmatism $(p<0.1)$. Emmetropisation occurred in the preterm infants so that at term age they did not differ from the fullterm group in astigmatism or anisometropia. However, preterm infants remained more myopic (less hyperopic) than the fullterm group at term $(p<0.05)$ and those infants born $<1500 \mathrm{~g}$ remained more anisometropic than their peers until 6 months $(p<0.05)$. Infants with abnormal cranial ultrasound were at risk for higher hyperopia $(p<0.05)$. Other clinical risk factors were not associated with differences in refractive development. At 4 years of age 19\% of the preterm group had clinically significant refractive errors.

Conclusion: Preterm infants without ROP had high rates of refractive error. The early emmetropisation process differed from that of the fullterm group but neither clinical risk factors nor measures of early refractive error were predictive of refractive outcome at 4 years.
$\mathrm{H}$ igh refractive errors are common in the neonatal period following fullterm and preterm birth. ${ }^{1-12}$ Fullterm neonates commonly demonstrate high levels of hyperopia and astigmatism that reduce rapidly during the first year of life. ${ }^{12}$ Ingram et al found this process, known as emmetropisation, to be complete in $82 \%$ of full term infants by 12 months of age. ${ }^{13}$ Emmetropisation has also been described for preterm infants who tend to be more myopic and astigmatic at birth than fullterm infants. ${ }^{12}{ }^{14-19}$ Among preterm infants with retinopathy of prematurity (ROP) in the neonatal period, a proportion demonstrate increasing myopia from 6 months corrected age onwards. The proportion of infants affected and the degree of myopia is higher when neonatal ROP is severe. $^{182021}$ This myopia is retained beyond infancy into childhood. ${ }^{4192-24}$ Although these findings suggest a link between ROP and myopia, prematurity (or low birth weight) may also impact on refractive development when ROP is absent or clinically undetectable. ${ }^{23} 25$ Some authors have reported that infants who do not develop ROP demonstrate a more normal pattern of refractive development. ${ }^{142326-29}$ Others find these infants have an increased risk for developing significant refractive errors, in particular myopia. ${ }^{19-21} 23-253031$

Fielder and Quinn's editorial eloquently summarises the associations between prematurity, ROP, and myopia. ${ }^{32}$ While the three are clearly linked, the relation between them is not well defined. They highlight the need to more fully understand the processes involved in refractive development of the visual system following preterm birth. Certainly, ROP increases the risk of myopia but even in its absence prematurity signals an increased risk for abnormal refractive development. Few reports on refractive outcome contain detailed information of the neonatal period. This study aimed to address this issue by excluding ROP as a factor and examining early refractive development in preterm infants without clinically detected eye disease and for whom extensive perinatal data are available. Refractive data are related to a fullterm group and to neonatal findings including cranial ultrasound.

\section{MATERIALS AND METHODS}

Full, informed consent was gained before testing and the protocol adhered to the tenets of the Helsinki Declaration of 1975, as revised in 1983 and was approved by the ethics committee of the Yorkhill NHS Trust. All refractive testing was performed by authors KJS and DLM. Brain imaging data were collected and analysed by AGW.

Subjects were 59 preterm infants without clinically diagnosed ROP (mean gestation 31.6 weeks, range 28-35, average weight $1.72 \mathrm{~kg}$ ) and 39 fullterm infants (mean gestation 40.3 weeks, average weight $3.47 \mathrm{~kg}$ ).

The authors tested all preterm infants born less than 35 weeks' gestational age who were well enough to be handled within 5 days of birth. Preterm infants in the unit were screened fortnightly for ROP from 6 weeks after birth until around term age. Screening was performed by an experienced ophthalmologist using indirect ophthalmoscopy through dilated pupils with a speculum and scleral indentation. Weekly screening between 34-37 weeks' gestational age was instigated for those babies considered at risk for developing severe ROP. Only babies for whom no abnormal findings were recorded at any stage or to any degree were enrolled into the follow up study and included in the current analysis.

Refraction was performed by retinoscopy without the use of a speculum 30 minutes after instillation of two drops of $0.5 \%$ cyclopentolate $\mathrm{HCl}$ in each eye. Where necessary, to permit viewing lids were lightly held without deformation of the globe. All subjects were refracted within 5 days of birth and invited to participate in further refractions (1.0\% cyclopentolate $\mathrm{HCl})$ at term age $(+/-1$ week) (preterms only), 6 months (+/- 2 weeks), 12 months (+/-SD 2 weeks), and 4 years $(+/-4$ months) corrected age (preterms only). It was not always possible to test every child at each test age because of poor health and failure to attend recall. The numbers refracted at each age are given in Table 1.

Testing was performed on the low dependency neonatal wards and in the special care baby unit at the Queen Mother's Hospital, Glasgow during the babies' stay in hospital and in an 
Table 1 Numbers of preterm and fullterm infants refracted at different test ages

\begin{tabular}{|c|c|c|c|c|c|}
\hline & \multicolumn{5}{|l|}{ Age at test } \\
\hline & Preterm birth & Term & 6 months & 12 months & 4 years \\
\hline Preterm subjects & 52 & 40 & 27 & 30 & 26 \\
\hline Fullterm subjects & - & 38 & 19 & 7 & - \\
\hline
\end{tabular}

\begin{tabular}{|c|c|c|c|c|c|c|c|}
\hline \multirow[b]{2}{*}{ (Corrected) age } & \multirow[b]{2}{*}{ Study group } & \multicolumn{2}{|c|}{ MSE (D) } & \multicolumn{2}{|c|}{ Astigmatism (D) } & \multicolumn{2}{|c|}{ Anisometropia (D) } \\
\hline & & Mean & SD & Mean & SD & Mean & SD \\
\hline \multirow[t]{2}{*}{ Birth } & Preterm & $0.47^{*}$ & 2.366 & 1.34 & 1.812 & $0.97^{*}$ & 1.191 \\
\hline & Full term & $3.47^{*}$ & 1.721 & 0.78 & 1.064 & $0.40^{*}$ & 0.663 \\
\hline \multirow[t]{2}{*}{ Term } & Preterm & $0.87^{*}$ & 1.723 & 0.66 & 0.786 & 0.32 & 0.475 \\
\hline & Full term & $3.47^{*}$ & 1.721 & 0.78 & 1.064 & 0.40 & 0.663 \\
\hline \multirow[t]{2}{*}{6 months } & Preterm & 2.07 & 1.682 & 0.82 & 0.890 & 0.30 & 0.603 \\
\hline & Full term & 2.36 & 0.879 & 0.61 & 0.826 & 0.07 & 0.211 \\
\hline \multirow[t]{2}{*}{12 months } & Preterm & 1.86 & 1.419 & 0.45 & 0.566 & 0.12 & 0.376 \\
\hline & Full term & 1.11 & 0.405 & 0.36 & 0.748 & 0.11 & 0.197 \\
\hline 4 years & Preterm & 1.64 & 1.430 & 0.24 & 0.444 & 0.16 & 0.447 \\
\hline
\end{tabular}

Means and standard deviations (SD) for fullterm and preterm infants and different test ages. Data from fullterm infants at birth are replicated for term age comparison with preterm group.

MSE = mean spherical equivalent.

*Denotes a statistically significant difference between preterm and fullterm groups at the $5 \%$ level.

outpatients department after discharge. Nineteen preterm infants were either twins or triplets: 15 of these were related (that is, one set of triplets, six sets of twins), the others were the only survivors of twin/triplet pregnancies. Exclusion of data from related subjects was considered. However, examination of the data suggested that their inclusion did not alter the outcomes of the analyses presented. All fullterm subjects were singleton births. Clinical data gathered during the perinatal period including cranial ultrasound findings, gestational age, birth weight, number of days on oxygen, and other routine data were recorded. Data regarding family ocular history, and refraction are not available.

\section{RESULTS}

Refractive data presented are levels of astigmatic error, mean spherical equivalent (spherical error plus half the astigmatic error), and anisometropia (difference in mean spherical equivalent between right and left eyes) (Table 2). The mean spherical equivalent (MSE) is commonly used and allows comparison with other published reports. Data presented are for left eye only. Right eye data demonstrate comparable findings.

Where categorised refractive error data have been used for analyses, the categories are as follows ${ }^{25}$;

significant hyperopia $>+3.00 \mathrm{D}$ MSE

myopia 0 to $\leqslant-3.00 \mathrm{D}$ MSE

high myopia $<-3.00 \mathrm{D}$ MSE

significant astigmatism $\geqslant 1.00 \mathrm{D}$

significant anisometropia $\geqslant 1.00 \mathrm{D}$ difference in the spherical equivalent between the two eyes

with the rule astigmatism (WTR), positive cylinder axis $90^{\circ}$ $\left(+/-15^{\circ}\right)$ - that is, vertical meridian having greater refractive power than the horizontal meridian

against the rule astigmatism (ATR), positive cylinder axis $180^{\circ}$ $\left(+/-15^{\circ}\right)$ - that is, horizontal meridian having greater refractive power than the vertical meridian

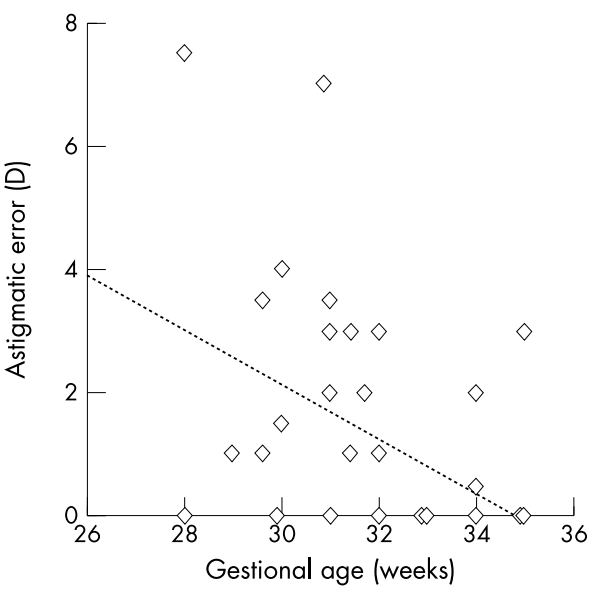

Figure 1 Relation between gestational age and astigmatic error at birth for preterm infants.

Oblique astigmatism, all other cylinder axes.

Refractive status and clinical risk factors

Birth weight and gestational age

The amount of astigmatism present at birth decreased with gestational age (regression analysis, $r^{2}=0.19, \mathrm{p}<0.05$ ), and similarly there was less astigmatism when birth weight was higher (regression analysis, $r^{2}=0.1, p<0.05$ ). A multiple regression analysis identified gestational age as the more important factor relating to astigmatic error; the earlier a baby was born the higher their astigmatic error tended to be $(p<0.05)$ (Fig l). However, there is considerable scatter in the data. By term age neither gestational age nor birth weight related to presence or level of astigmatism.

Preterm babies with lower birth weights $(<1500 \mathrm{~g})$ and those born more prematurely ( $<33$ weeks' gestation) were significantly more likely to demonstrate anisometropia 

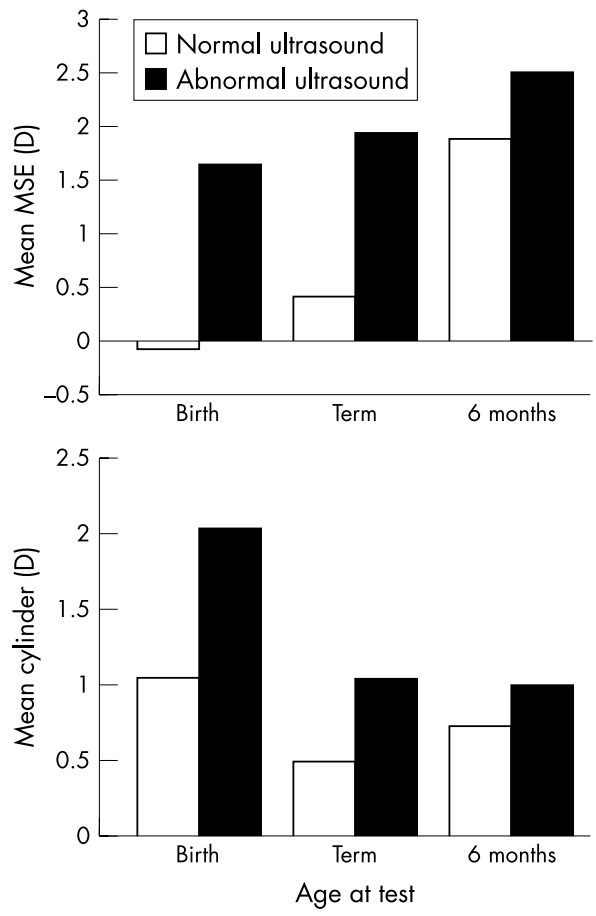

Figure 2 Effect of abnormal cranial ultrasound on MSE and astigmatism at birth among preterm infants.

$(\geqslant 1.00 \mathrm{D})$ at birth than their peers $\left(\chi^{2} \mathrm{p}<0.05\right)$. Most infants showed a reduction in anisometropia with increasing age, but those with the lowest birth weights $(<1500 \mathrm{~g})$ were still more likely to be anisometropic than their peers at 6 months of age $\left(\chi^{2} \mathrm{p}<0.05\right)$. By 12 months of age this association was lost.

MSE was extremely variable among preterm infants, ranging from $-5.00 \mathrm{D}$ to $+4.50 \mathrm{D}$. Those with lower birth weight were more likely to be myopic (linear regression $r^{2}=0.036$, $\mathrm{p}<0.05$ ) but these data showed a great deal of scatter as indicated by the $r^{2}$ value. While spherical errors also tended to be more myopic in infants with lower gestational ages this relation failed to reach significance.

\section{Cranial ultrasound}

Of the 59 preterm infants tested, 19 had an abnormal result recorded with cranial ultrasound. Abnormal results included any of the following; periventricular cysts, increase in periventricular echogenicity, irregularity of the ventricular walls, presence of ventricular dilatation, parenchymal abnormalities, and the presence of intraventricular haemorrhage. Preterm babies with an abnormal cranial ultrasound result recorded in the neonatal period were significantly more hyperopic and astigmatic at birth and term age (ANOVA $\mathrm{p}<0.05$ ) (Fig 2). Those with abnormal cranial ultrasound features tended to be those with lower gestational ages. Infants born at earlier gestational ages have more astigmatism (see above) and they are also at greater risk for cranial ultrasound abnormalities. Therefore, the association between cranial ultrasound abnormalities and astigmatism at birth is predictable. However, prematurity and low birth weight are associated with myopia so the higher levels of hyperopia in those with abnormal cranial ultrasound results is unexpected and may suggest that other risk factors are involved. In particular irregularities, dilatation and intraventricular haemorrhage were most strongly predictive of early hyperopic errors. A multiple regression analysis relating birth weight, gestational age, and cranial ultrasound to spherical error at birth highlighted only abnormal cranial ultrasound as a statistically significant variable $(\mathrm{p}<0.05)$.
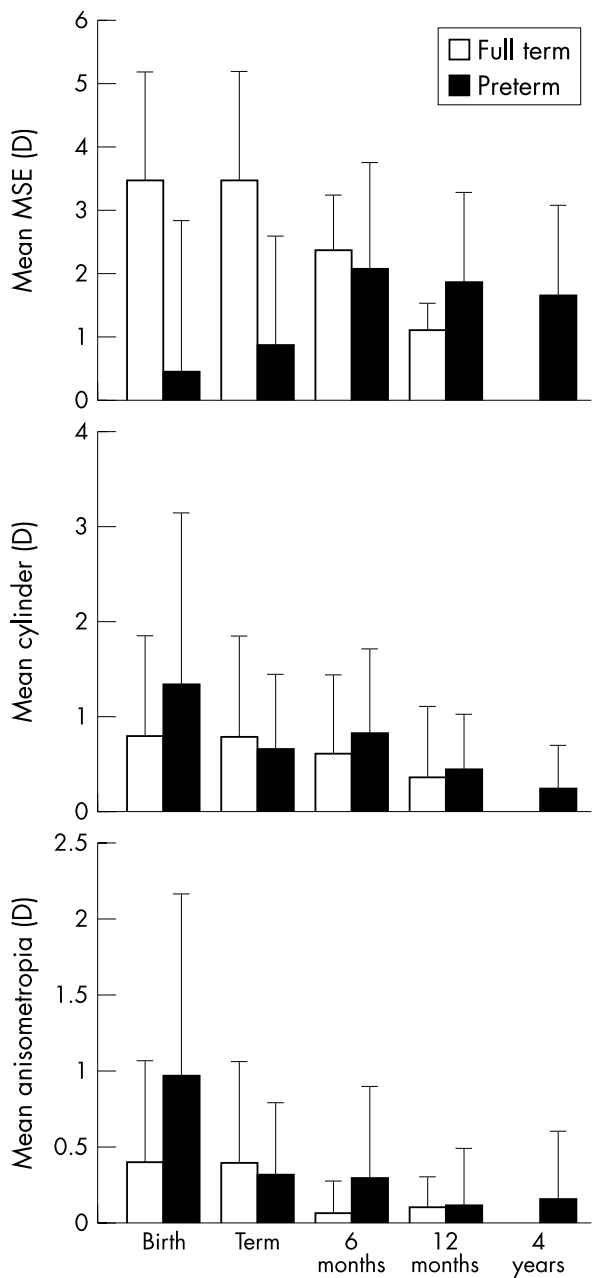

Figure 3 Mean refractive errors of preterm and fullterm infants.

\section{Other neonatal risk factors}

None of the following neonatal risk factors significantly related to any aspect of refractive status at any age; number of days on oxygen, Apgar score at 1, 5, or 10 minutes, lowest recorded level of blood oxygen, or highest recorded level of blood carbon dioxide

\section{Refractive status in the first year of life}

Preterm infants without ROP demonstrated significantly higher levels of anisometropia and myopia at birth than fullterm infants (ANOVA $\mathrm{p}<0.05$ ) and a tendency for more astigmatism (ANOVA $\mathrm{p}<0.1$ ) (Fig 3, Table 2). Term infants all demonstrated WTR astigmatism at birth. Preterm infants had greater variability in axes; 13 ATR, seven WTR, and eight oblique $\left(\chi^{2} \mathrm{p}<0.05\right)$. Oblique errors tended to be higher than those in other meridians (ANOVA $\mathrm{p}<0.1$ ).

At term age there was an increase in hyperopia among the preterm infants but they were still significantly less hyperopic MSE (ANOVA $p<0.05$ ) than fullterm infants at birth (Fig 3). The preterm infants also showed a reduction in anisometropia and astigmatism by term age (repeat measures ANOVA $p<0.05$ and $p<0.1$ respectively), and these factors no longer differed in magnitude when compared with fullterm infants at birth (Fig 3). Preterm infants still demonstrated significantly more non-WTR axes of astigmatism $\left(\chi^{2} p<0.05\right)$ but many of those with oblique errors at birth had WTR errors by this age. Those with ATR errors at birth tended to maintain this axis at least until term age.

Between term age and 6 months corrected age the preterm group demonstrated a further increase in hyperopia (repeat 
Table 3 Prevalence of significant refractive errors for preterm infants at different test ages

\begin{tabular}{llllll}
\hline \multirow{2}{*}{ Age (total No) } & \multicolumn{3}{l}{ Incidence (\%) (No) } & & \\
\cline { 2 - 5 } & High myopia & Myopia & Hyperopia & Astigmatism & Anisometropia \\
\hline Birth (52) & $5.8(3)$ & $32.7(17)$ & $15.4(8)$ & $48.1(25)$ & $35.4(17)$ \\
Term (40) & 0 & $17.5(7)$ & $7.5(3)$ & $45.0(18)$ & $18.4(7)$ \\
6 months (27) & 0 & $3.7(1)$ & $18.5(5)$ & $48.2(13)$ & $14.8(4)$ \\
12 months (30) & 0 & 0 & $16.7(5)$ & $26.7(8)$ & $7.3(1)$ \\
4 years (26) & 0 & $3.8(1)$ & $11.5(3)$ & $7.7(2)$ & $7.7(2)$ \\
\hline
\end{tabular}

measures ANOVA $\mathrm{p}<0.05$ ) and by 6 months corrected age did not differ significantly in any aspect of refractive status from the fullterm group (ANOVA p <0.05) (Fig 3). At 6 months corrected age the preterm group and fullterm group demonstrated no significant difference in the type of cylinder axis $\left(\chi^{2}\right.$ $p>0.05)$. Those ATR errors still present at term age had either disappeared or become WTR by 6 months corrected age.

No significant changes in any aspect of refractive status occurred between 6 and 12 months corrected age. The full and preterm groups did not differ significantly in any aspect of refractive status at this age.

\section{Preterm follow up at 4 years}

Twenty six preterm infants were available for re-refraction at 4 years corrected age. Individuals demonstrated no significant change in MSE between 12 months and 4 years corrected age (repeat measures ANOVA p>0.05). In contrast, astigmatic errors showed a significant reduction during this time (repeat measures ANOVA $\mathrm{p}<0.05$ ).

At 4 years of age only one child was myopic (-3.00D MSE), the remainder of the group were hyperopic (range 0.50D5.00D MSE). Astigmatism over 1.00D was unusual. Only the myopic child (2.00D of astigmatism) and one other were astigmatic. Five (19\%) children had significant refractive errors that warranted spectacle correction. Three of these had more than one category of refractive error (Table 3 ).

There were no associations between refractive outcome at 12 months corrected age or at 4 years corrected age and any features of refractive status at birth or term age.

To test whether children available for refraction at 4 years were representative in terms of neonatal risk factors or early refractive history, they were compared with those unavailable for recall. Contingency table analyses highlighted an association between non-attendance at 4 year recall, extremely low birth weight $(<1000 \mathrm{~g})$, and/or abnormal cranial ultrasound in the neonatal period $(\mathrm{p}<0.05)$. Refractive history was not related to attendance at 4 years.

\section{Emmetropisation and preterm birth}

Infants born at term typically show a reduction in refractive error during the first year of life. This emmetropisation occurs more rapidly for high neonatal errors. ${ }^{33}$ Twenty eight preterm infants had been repeatedly refracted under cycloplegia (within 5 days of birth, term age, and either 6 and/or 12 months corrected age). Fourteen fullterm subjects were also repeatedly refracted. The data from these infants allowed the investigators to examine emmetropisation in the first year following preterm birth.

Fullterm infants in the present study demonstrated the expected relation between magnitude of refractive error at birth and the rate at which it reduced (regression analysis $\mathrm{p}<0.05)$. Emmetropisation in this group resulted in low levels of hyperopia with little or no anisometropia or astigmatism by the end of the first year of life. Only one fullterm infant had a significant level of persistent astigmatism (2.00D) present from birth.

Preterm infants also showed evidence of emmetropisation and the rate at which MSE reduced was related to the magni- tude recorded at birth (regression analysis $p<0.05$ ). The data for those fullterm and preterm infants tested repeatedly during the first year of life are illustrated in Figure 4. The preterm data have been divided into four groups; those showing a reduction in hyperopia with increasing age similar to that seen in the fullterm group (Fig 4B), those preterm infants showing a reduction in myopia (Fig 4C), those with increased hyperopia during the first year of life (Fig 4D) and those who demonstrated an erratic pattern of refractive development (Fig 4E). The groups were chosen for presentation purposes and help to reveal refractive development trends within the group.

Emmetropisation was also judged to have occurred in many of those infants who were born prematurely (54\%) (Figs 4B, C). Refractions among these infants at 12 months were not distinguishable from the fullterm infants even though they had demonstrated more myopia at term age than their fullterm peers. However, a substantial proportion (46\%) of infants born prematurely either retained or developed clinically significant hyperopia (Fig 4D) or demonstrated erratic patterns of refractive development (Fig 4E). None of the preterm infants tested retained myopia beyond 6 months corrected age and only one was myopic $(-3.00 \mathrm{D})$ at 4 years of age. Most astigmatic and anisometropic errors were lost during the first year of life. Only three infants demonstrated significant levels of astigmatism and/or anisometropia beyond 12 months corrected age. Two of these three infants weighed less than $1500 \mathrm{~g}$ at birth.

None of the neonatal factors, either clinical or refractive, has significant predictive associations with patterns of refractive development or outcome $\left(\chi^{2} \mathrm{p}>0.05\right)$. For example, although premature infants had significantly higher levels of ATR and oblique astigmatism at birth neither were associated with future refractive development.

\section{DISCUSSION}

Emmetropisation occurs in fullterm infants and fails in relatively few. ${ }^{12}$

Preterm children with ROP often dramatically fail to emmetropise, resulting in high levels of refractive error, most notably myopia. ${ }^{48-24}$ The present study examined the impact of preterm birth on refractive status and development in the absence of ROP. We have shown that children from our clinical population without ROP fall somewhere between fullterm infants and preterm infants with ROP and as such warrant monitoring.

During the first months of life preterm infants demonstrated more myopia, astigmatism, and anisometropia than fullterm infants. ${ }^{12414-19}$ Astigmatic axes among preterm infants in the neonatal period have previously been described as mainly ATR and this is supported by the present study. This contrasts with fullterm infants whose astigmatism was uniquely WTR. In the present study, infants born preterm either lost their astigmatism or in many cases it became WTR by 6 months corrected age. This conversion occurred more rapidly for oblique errors. Infants in the present study who were born with lower birth weights and/or gestational ages 

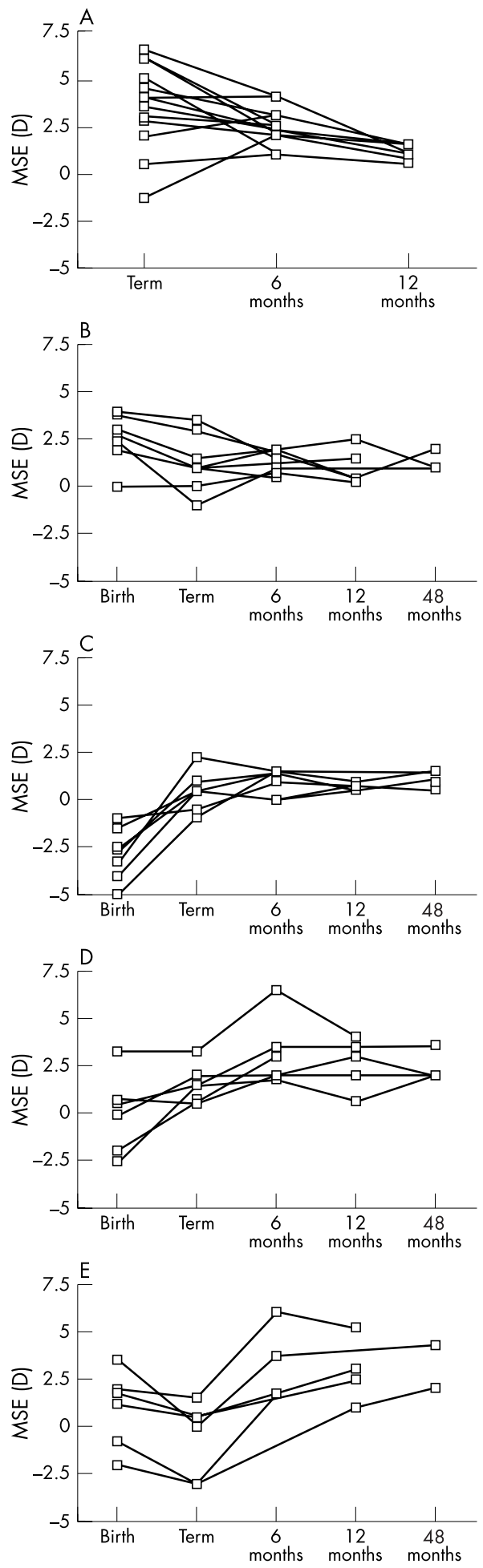

Figure 4 Individual refractive data for fullterm (A) and preterm infants $(B-E)$ refracted repeatedly.

were more astigmatic and had a higher incidence of significant anisometropia than larger or older babies. Dobson et $a l^{4}$ also reported an inverse relation between gestational age and cylinder power. Unlike the present study they found a significant association between spherical error and gestational age, with the youngest infants being more myopic. The present study failed to demonstrate this association but found that smaller babies were more myopic at birth. Because of the close association between birth age and birth weight it is not easy to discriminate between the effect of early birth and small size on refractive components. The data of the present study support the suggestion that it is the small size of the preterm infant and presumably the infant eye that results in neonatal myopia. While the eye may be smaller in length (which would promote hyperopia) the reduced radius of curvature of the cornea and/or lens would promote myopia. Fledelius ${ }^{17}$ found no relation between axial length at birth and refractive status in premature infants. Gallo and Fagerholm ${ }^{35}$ and Tane et $a^{36}$ suggest that, in contrast with myopia in those born at term, which can be attributed to increased axial length, ${ }^{37}$ neonatal myopia associated with prematurity is explained by increased corneal curvature. Fletcher and Brandon ${ }^{1}$ state that a decrease in the anterior radius of curvature of only $0.4 \mathrm{~mm}$ would increase myopia by 16D. Even at the age of 10 years ex-preterm children have shorter axial lengths, more curved corneas, and thicker crystalline lenses. ${ }^{38}$ Fledelius attributes this failure in preterm eyes to follow "normal" biometric patterns to the shock delivered to the eye by preterm delivery which "arrests subsequent eye development and growth." It would seem that the fetal proportions apparent at birth are not altogether compensated for by growth and visual experience.

While several authors have stated that the early myopic, astigmatic, and anisometropic errors associated with preterm birth often reduce in the absence of ROP, it is not clear from the literature when parity with fullterm cohorts is achieved. ${ }^{14-19}$ The present study's preterm group did not differ significantly from the fullterm group in any aspect of refractive status by 6 months corrected age.

Data from individual preterm infants monitored prospectively during the first year of life demonstrate that preterm birth not only affects refractive status at birth but may impact on its early development. It appears that in the absence of ROP the immature eye and visual system of the preterm infant is capable of "catching up" with fullterm infants. However, this process does not occur in the time taken to reach term age but rather takes up to 6 months. The emmetropisation process, which is active in the normal visual system during this time, involves a visual feedback mechanism that promotes and maintains emmetropia. These data suggest that in the absence of ROP the emmetropisation process is often able to correct the abnormal refractive errors associated with preterm birth. The myopia, astigmatism, and anisometropia demonstrated by the preterm group in the neonatal period are reduced and the highest errors reduce most rapidly as they do in the fullterm infant. However, when data from individual infants tested longitudinally are examined it can be seen from this cohort that the patterns of refractive development demonstrated by many are more erratic than those of our fullterm infants and than those expected from the literature describing normal refractive development. This suggests some impedance to the ongoing emmetropisation process in a substantial proportion of infants following preterm birth. No associations were found between clinical risk factors or early refraction and refractive outcome, and further prospective investigation of larger numbers of infants, also considering the influence of other factors such as family ocular history, would be useful. Failure to emmetropise may not necessarily result only in myopia but in increased refractive errors of other types as has been shown by Holmstrom et $a l^{25}$ and Tupperainen et al. ${ }^{22}$ The outcome at 4 years of children available for follow up supports this idea. Of 26 children tested at 4 years five required spectacle correction. Only one was myopic $(-3.00 \mathrm{D})$ but three had significant hyperopia, two were significantly astigmatic, and two were anisometropic. While the numbers are small these figures are larger than expected from studies of fullterm children of this age. ${ }^{39-41}$ In addition to refractive problems three children were strabismic at 4 years, a higher percentage than the 1-5\% expected from the fullterm population. ${ }^{42}$ It should be noted that those children available for recall at 4 years were less likely to have had the most severe problems at birth 
(extremely low birth weight, abnormal cranial ultrasound)that is, those who might be predicted to have more ocular morbidity than their peers.

The data of the present study demonstrate little association between refractive status and clinical risk factors other than ROP. An interesting association between infants with abnormal cranial ultrasound in the neonatal period and early hyperopia was found but too few infants with such abnormalities were available to follow up to examine whether this was a transient or predictive finding and it warrants further study. Abnormal neonatal cranial ultrasound were noted for $26.5 \%$ of the preterm infants in Laws et al' ${ }^{18}$ cohort but no relation between cranial ultrasound findings and refractive error is reported.

While it seems that ROP may be the most important factor associated with the development of myopia following preterm birth, even in its absence monitoring of refractive and visual outcome is necessary. It is unwise to restrict ophthalmic follow up only to those with ROP.

\section{ACKNOWLEDGEMENTS}

The authors would like to express their gratitude to all the children and parents who participated in the study. We are also grateful to the staff of the low dependency neonatal wards and the special care baby unit at the Queen Mother's Hospital, Glasgow, in particular Drs Tom Turner and John Dudgeon. Thanks are also due to Maureen McElroy for her help in contacting subjects and arranging the 4 year recall. Helpful comments from the reviewers of this paper were also gratefully received.

AJS was supported by SOHHD, chief scientists office grant K/RED4/ C265.

\section{Authors' affiliations}

K J Saunders, School of Biomedical Sciences, University of Ulster, Coleraine, Northern Ireland, BT52 1SA, UK

D L McCulloch, Department of Vision Sciences, Glasgow Caledonian University, Glasgow, Scotland, UK

A J Shepherd, Department of Nursing and Midwifery, University of Stirling, Stirling, Scotland, UK

A G Wilkinson, Department of Radiology, The Royal Hospital for Sick Children, Edinburgh, Scotland, UK

\section{REFERENCES}

1 Fletcher MC, Brandon S. Myopia of prematurity. Am J Ophthalmol 1955;40:474-81.

2 Graham MV, Gray OP. Refraction of premature babies' eyes. BM 1963;i: 1452-4.

3 Shapiro A, Yanko L, Nawratzki I, et al. Refractive power of premature children at infancy and early childhood. Am J Ophthalmol 1980:90:234-8.

4 Dobson V, Fulton AB, Manning K, et al. Cycloplegic refractions of premature infants. Am J Ophthalmol 1981;91:490-5.

5 Gordon RA, Donzis PB. Myopia associated with retinopathy of prematurity. Ophthalmology 1986;93:1593-8.

6 Gibson NA, Fielder AR Trounce JQ, et al. Ophthalmic findings in infants of very low birthweight. Dev Med Child Neurol 1990;32:7-13.

7 Grose J, Harding G. The development of refractive error and pattern visually evoked potentials in pre-term infants. Clin Vis $\mathrm{Sci}$ 1990:5:375-82

8 Koole FD, Bax PP, Samson JF, et al. Ocular examination in nine-month-old infants with very low birthweights. Ophthalmic Paediatr Genet 1990;11:89-94

9 Gallo JE, Lennerstrand G. A population based study of ocular abnormalities in premature children aged 5 to 10 years. Am J Ophthalmol 1991;111:539-47.

10 Fielder AR, Foreman N, Moseley M, et al. Prematurity and visual development. In: Simons K, ed. Early visual development, normal and abnormal. New York: Oxford University Press, 1993:485-504.
11 Page JM, Schneeweiss S, Whyte HEA et al. Ocular sequelae in premature infants. Paediatrics 1993;92:787-90.

12 Saunders KJ. Early refractive development in humans. Surv Ophthalmol 1995;40:207-16

13 Ingram RM, Arnold PE, Dally S, et al. Emmetropisation, squint, and reduced visual acuity after treatment. Br J Ophthalmol 1991:75:414-16.

14 Scharf J, Zonis S, Zeltzer M. Refraction in Israeli premature babies. J Pediatr Ophthalmol 1975;12:193-6.

15 McCormick AQ, Tredger EM, Dunn HG, et al. Ophthalmic disorders. In Dunn HG, ed. Sequelae of low birthweight, the Vancouver study. Clinics in developmental medicine 95-96. Oxford: Mackeith Press, Blackwell Scientific Publications, 1986:127-46.

16 Rodriguez A, Villarreal J, Homar Paez J. Visual acuity and retinoscopy of preterm and full-term infants during the first year of life. Ann Ophthalmol 1996;28:46-53.

17 Fledelius HC. Preterm delivery and the growth of the eye. An oculometric study of eye size around term-time. Acta Ophthalmol 1992;204 (suppl): 10-15.

18 Laws D, Shaw DE, Robinson J, et al. Retinopathy of prematurity: a prospective study. Review at six months. Eye 1992;6:477-83.

19 Quinn GE, Dobson V, Repka MX, et al. Development of myopia in infants with birth weights less than 1251 grams. They Cryotherapy for Retinopathy of Prematurity Cooperative Group. Ophthalmology 1992:99:329-40.

20 Nissenkorn I, Yassur Y, Mashkowski D, et al. Myopia in premature babies with and without retinopathy of prematurity. Br J Ophthalmol 1983;67:170-3

21 Robinson R, O'Keefe M. Follow-up study on premature infants with and without retinopathy of prematurity. Br J Ophthalmol 1993;77:91-4.

22 Tupperainen K, Herrgård E, Martikainen A, et al. Ocular findings in prematurely born children at 5 years of age. Graefes Arch Clin Exp Ophthalmol 1993;231:261-6.

23 Fledelius HC. Preterm delivery and subsequent ocular development. A 7-10 year follow-up of children screened 1982-84 for ROP. 31 Refraction. Myopia of prematurity. Acta Ophthalmol Scand 1996;74:297-300.

24 Hebbandi SB, Bowen JR, Hipwell GC, et al. Ocular sequelae in extremely premature infants at 5 years of age. J Paediatr Child Health 1997;33:339-42.

25 Holmstrom G, el Azazi M, Kugelberg U. Ophthalmological long term follow up of preterm infants: a population based, prospective study of the refraction and its development. Br J Ophthalmol 1998;82:1265-71.

26 Kushner BJ. Strabismus and amblyopia associated with retinopathy of prematurity. Arch Ophthalmol 1982;100:256-61

27 Schaffer DB, Quinn GE, Johnson L. Sequelae of arrested mild retinopathy of prematurity. Arch Ophthalmol 1984;102:373-6.

28 Pennefather PM, Tin W, Strong NP, et al. Refractive errors in children born before 32 weeks gestation. Eye 1997;11:736-43.

29 Saw SM, Chew SJ. Myopia in children born premature or with low birth weight. Acta Ophthalmol Scand 1997;75:548-50.

30 Keith CG, Kitchen WH. Ocular morbidity in infants of very low birth weight. Br J Ophthalmol 1983;67:302-5.

31 Cats B, Tan KEWP. Prematures with and without regressed retinopathy of prematurity: comparison of long-term (6-10 years) ophthalmological morbidity. J Pediatr Ophthalmol Strabismus 1989;26:271-5.

32 Fielder AR, Quinn GE. Myopia of prematurity: nature, nurture, or disease? Br J Ophthalmol 1997:81:2-3.

33 Saunders KJ, Woodhouse JM, Westall CA. Emmetropisation in human infancy: rate of change is related to initial refractive error. Vis Res 1995; 35:1325-8

34 Ehrlich DL, Braddick O, Atkinson J, et al. Infant emmetropization: longitudinal changes in refraction components from nine to twenty months of age. Optom Vis Sci 1997;74:822-845.

35 Gallo JE, Fagerholm P. Low-grade myopia in children with regressed retinopathy of prematurity. Acta Ophthalmol 1993;71:519-23.

36 Tane S, Ito S, Kushiro $\mathrm{H}$ et al. Echographic biometry in myopia of prematurity. Jap J Clin Ophthalmol 1978;32:622-5.

37 Goss DA. Myopia in childhood. In: Grosvenor, Flom, ed. Refractive anomalies. Oxford: Butterworth-Heinemann, 1991:81-103.

38 Fledelius HC. Prematurity and the eye. Ophthalmic follow-up of children of low and normal birthweight. Acta Ophthalmol 1976;128 (suppl): 1-245.

39 Quinn GE, Dobson V, Kivlin J, et al. Prevalence of myopia between 3 months and $51 / 2$ years in preterm infants with and without retinopathy of prematurity. Ophthalmology 1998;105: 1292-300.

40 Köhler L, Stigmar G. Vision screening of four-year-old children. Acta Paediatr Scand 1973;62:17-27.

41 Hirsch MJ. Changes in astigmatism during the first eight years of school-an interim report from the Ojai longitudinal study. Am J Optom Arch Acad Optom 1963;40:127-132.

42 Lyle WM. In: Genetic risks: a manual for eye care practitioners. University of Waterloo Press, 1990. 